\title{
Unusual Renal Tumors Report of Four Cases
}

Authors- Punit Tiwari ${ }^{1}(\mathrm{MS})$, Astha Tripathi ${ }^{2}$ (MD),Suresh Kumar ${ }^{1}(\mathrm{MS})$, Pramod Sharma $^{1}$ (MS),Amit

Goel $^{1}(\mathrm{MS})$, Dipankar Gayen $^{\mathbf{1}}(\mathrm{MS}), \mathbf{M ~ K ~ B e r a}^{1}(\mathrm{MCh}) \mathbf{A}$ K Kundu${ }^{1}(\mathrm{MCh})$ Affiliations:1- Dept Of Urology,Institute of Post Graduate Medical Education \& Research ,Kolkata,(WB),India, 2-Department of Paediatrics, Institute of Post Graduate Medical Education \& Research ,Kolkata,(WB),India. Correspondence: Dr.Punit Tiwari,(MS). E-mail: id-punitms@rediffmail.com

\section{Summary}

Collecting duct carcinoma, plasmocytoma and malignant fibrous histocytoma are rare but aggressive tumors of the kidneys. We present four cases we have recently encountered in our practice. In most of the cases imaging did not help in the pre-operative diagnosis. Surgery is the mainstay of treatment when recognized early. Clinician should be aware about these rare varieties of renal tumors whose prognoses may be worse than that of renal cell carcinoma.

\section{Introduction}

Collecting duct carcinoma, plasmacytoma and malignant fibrous histiocytoma are rare tumors of the kidneys. Less than 100 cases of collecting duct carcinoma are reported in the literature(1-2) while plasmacytoma occurs with a worldwide annual incidence of 3 per 100,000 population There are no differentiating radiological features of renal plasmacytoma from renal cell carcinoma.

Malignant fibrous histiocytoma represents a primitive mesenchymal tumor with partial fibroblastic and histiocytic differentiation. Renal involvement comprise only 1-3\%. We report four cases encountered in our recent practice and review the relevant literature

\section{Case 1}

48 yrs old male presented with intermittent painless gross hematuria and loss of weight for one month. Renal ultrasound showed an irregular mass in the region of left kidney associated mild hydronephrosis. It enhanced on CT-scanning. No retroperitoneal lymphadenopathy was demonstrated (Fig 1). The patient was subjected to left radical nephrectomy. Grossly, the resected kidney showed a central gray-white growth extending from mid pole into the renal pelvis. Histology confirmed features of collecting duct carcinoma penetrating the capsule and perinephric in areas (Fig 1). The patient developed lung and bone metastases eight months after surgery and died two months later.

\section{Case 2}

A 55-year-old man presented with two months history of painless hematuria. Renal ultrasound showed an irregular lesion in upper pole of right kidney which enhanced on the subsequent CT scan. The radical nephrectomy specimen showed an ill- defined and pale cream irregular mass measuring $6 \mathrm{~cm}$ in diameter. Histolopathological examination confirmed a collecting duct carcinoma (Fig 1). The patient is on regular follow up and is currently free of the disease two years after surgery.

\section{Case 3}

A 56 years old male patient presented with history of pain in his right lumbar region for three months. He had no history of hematuria, stone disease, hypertension, diabetes, weight loss or loss of appetite. Physical examination revealed a ballotable lump in right lumbar region. His haemoglobin was $12.8 \mathrm{~g} / \mathrm{dl}$, total leukocyte count 7,800/mm3 (neutrophils $68 \%$, lymphocyte $24 \%$, eosinophill $5 \%$ and basophills $3 \%$ ). His renal and liver function tests were also normal. Serum calcium was $9.1 \mathrm{mg} \%$ and the chest X-ray was normal. Abdominal ultrasound revealed a mass occupying the lower half of right kidney. Contrast enhanced CT-scan showed a large heterogeneously enhancing mass involving the postero -medial aspect of right kidney (Figure 2). The surrounding fat planes were maintained and renal vessels were normal. Right radical nephrectomy was performed. The post operative period was uneventful. Histopathology of the resected specimen showed 
figure1A: Low power view showing many collecting ducts lined by atypical malignant epithelial lining cells embedded in a desmoplastic stroma. Collecting Duct Carcinoma. [HE Stain 10X].

Figure1B: Higher power view showing one normal glomerulus and numerous collecting ducts lined by lined by malignant epithelium, some places lining cells showing stratification. Surrounding stroma shows desmoplastic reaction - Collecting duct carcinoma. [HE Stain 40X].

Figure 1C-CT scan showing heterogenous mass involving Left Kidney
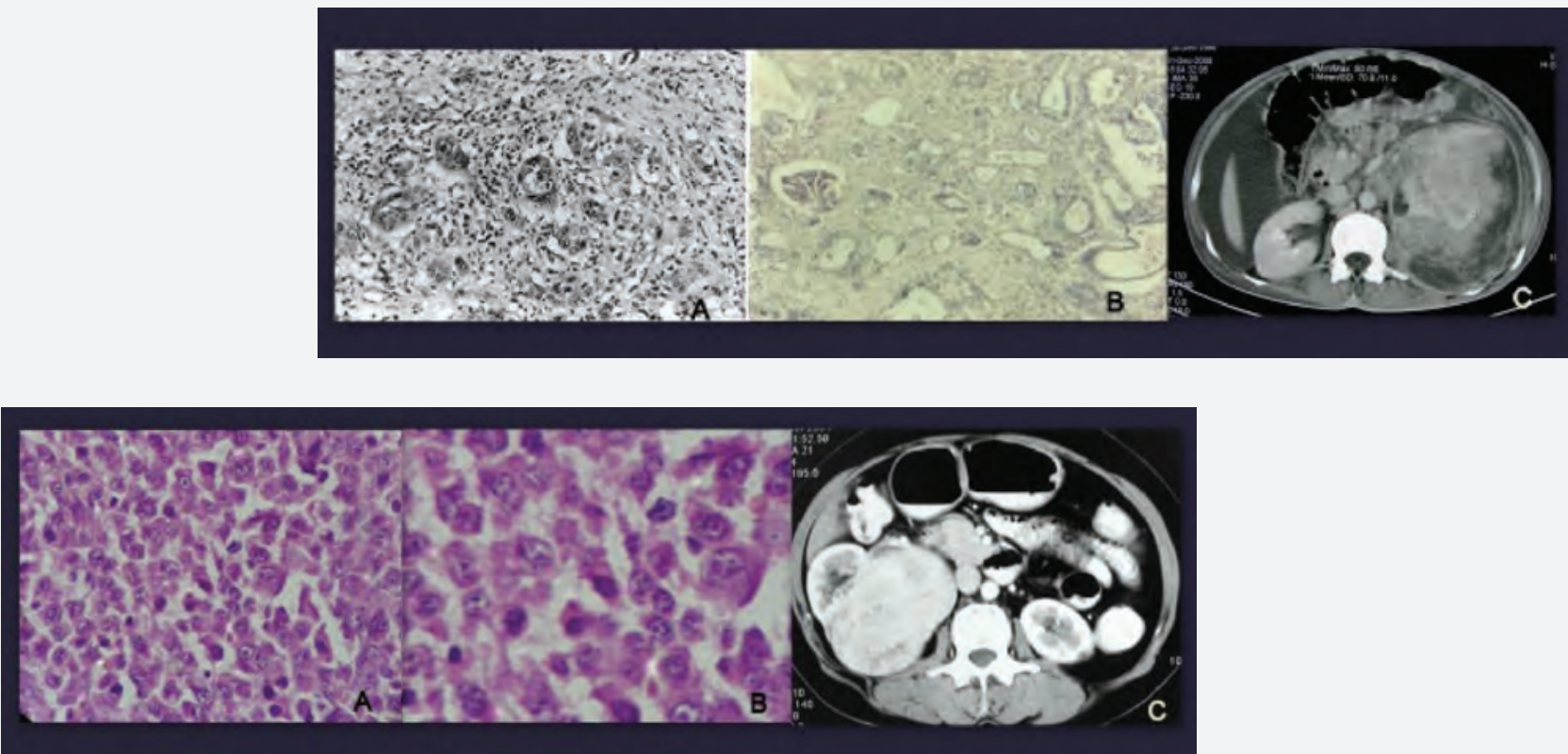

Figure2A: Section shows diffuse sheets of Plasma cells having eccentric nucleus and eosinophilic cytoplasm, PLASMACYTOMA [HE Stain 10X].

Figure 2C-CT scan showing a mass involving the right kidney
Figure2B: High power view shows numerous plasma cells having eosinophilic cytoplasm, eccentric nucleus and perinuclear hoff; there is pleomorphism among the cells. - Plasmacytoma [HE Stain 40X]. sheets of round monomorphic cells with vesicular and eccentric nucleus (Figure 2). Higher power view showed plasma cells with basophilic cytoplasm, eccentric nuclei and typical peripheral condensation of the chromatin (Figure 2). Lymph nodes were negative for tumor deposits. The tumor had positive immunostaining for lambda chains, vimentin, and VS38 but negative for kappa chains, cytokeratin (CK), MPO, CD45 and CD20. Urine Bence Jones proteins were negative, serum electrophoresis showed no M-band and bone marrow biopsy was normal. A final diagnosis of primary renal plasmacytoma was entertained. Adjuvant radiation therapy was given in doses of $45 \mathrm{~Gy}$ in 25 fractions. He remains disease free one year after diagnosis.

\section{Case 4}

A 65 years old male patient presented with history of gradual loss of weight for 8 months. He had no history of hematuria, stone disease, hypertension and diabetes. The main finding was a bimannually palpable lump in the left lumbar region. His hemoglobin was $10.0 \mathrm{~g} / \mathrm{dl}$, Urea $18 \mathrm{mg} \%$, Creatinine 0.7 $\mathrm{mg} \%$ and liver function test normal. Serum calcium measured $9.1 \mathrm{mg} \%$ and chest X-ray was normal. Ultrasound revealed a mass occupying the left kidney. Contrast enhanced CT-scan confirmed a large kidney tumor (Figure 3), normal renal vessels and perinephric fat planes. Histology of the radical nephrectomy specimen (Figure 3) showed spindle cells arranged in patchy storiform pattern with considerable nuclear pleomorphism, foci of necrosis and hyalinization which consistent with a diagnosis of malignant fibrous histocytoma. (Figure 3).

\section{Discussion}

Bellini duct carcinoma or collecting duct carcinoma (CDC) is a rare renal malignancy. It was established as a distinct en- 


\section{CASE REPORT}

\section{Unusual Renal Tumors - Case Reports and Review of Literature}

Punit Tiwari, Astha Tripathi, Suresh Kumar, Pramod Sharma, Amit Goel, Dipankar Gayen, M K Bera, A K Kundu

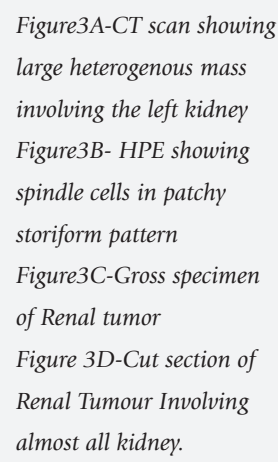

tity in 1986 by Fleming and Lewi as an aggressive tumor with mixed solid and tubulopapillary patterns eliciting a marked desmoplastic reaction (3). Initially grouped together with renal cell carcinoma and subdesigned 'Bellini duct carcinoma' , collecting duct carcinoma is presently recognized as a separate entity $(4,6)$

Less than 100 cases of collecting duct carcinoma have been reported in the literature, accounting for only about $1 \%$ of all malignant renal epithelial tumors (1-4).

Originating in the renal medulla and secondarily extending into the cortex, the tumor expresses phenotypic markers of the normal collecting duct including Ulex europaeus-1 lectin (UEA-1), peanut agglutinin (PNA) and high molecular weight cytokeratin (HMWK, 34+E12) (2) . Fifty percent of patients have metastatic disease at presentation $(1,2)$.

The majority of patients are treated by nephrectomy and regional lymph node dissection. Immunoactive agents such as interferon or interleukin, and combination chemotherapy for relapsed disease or metastatic lesions, usually seem to be ineffective (1) . At present, the number of reported cases of CDC is too small and with a short follow-up to make any real sur- vival assessment. However, the cases reported point to poor prognosis with average survival of approximately 12 months only (6).

Extramedullary plasmacytomas (EMP) occur with a worldwide annual incidence of 3 per 100,000 population and account for less than 3-10\% of all plasma cell neoplasms (7). Eighty to ninety percent of EMP develop in the head and neck area with the remainder in other sites. Extramedullary plasmacytoma affecting the kidney is very rare disease with only few case reports published in the literature (8).

Radiological findings in renal plasmacytoma are indistinguishable from those of renal cell carcinoma. Diagnostic criteria include tissue monoclonal plasma cells, bone marrow plasma cell infiltration not exceeding 5\% of all nucleated cells, absence of osteolytic bone lesions, absence of hypercalcemia or renal failure and low serum $M$ protein concentration, if present (9). In our case histopathology revealed plasmacytoma and immunohistochemistry showed monoclonal immunoglobulin and immunostaining for VS38 and negative for CD45 and CD20. VS38 is a newly available monoclonal antibody 
for detecting plasma cell differentiation in routine sections (10). It has been reported that failure to stain for CD45 and CD20 is highly characteristic for neoplastic plasma cells (11). Bone marrow biopsy, urinary Bence Jones Proteins and serum protein electrophoresis ordered for the patient ruled out systemic disease.

Soft tissue plasmacytoma can be classified into 3 clinical stages. Stage I, like in this case, is limited to an extramedullary site, Stage II involves regional lymph nodes while stage III presents with multiple metastasis (12). The optimal treatment is a combination of surgery, and radiotherapy (13).Chemotherapy using regimens used for multiple myeloma may be advisable for patients with generalized EMP, refractory or relapsed disease (14). Our patient has been free of local recurrence and systemic disease after one year of follow up Malignant fibrous histocytoma was first described by O'bren and Stout in 1964 (15). The histogenesis of the tumor is controversial. The tumor cells posses markers of both mesenchymal and mononuclear phagocytic cells (16). The disease has a poor prognosis with half of patients dead within one year and an overall five year survival rate less than $14 \%$ (17). Surgery is the main treatment. In recurrences, treatment with chemotherapy may be indicated while radiotherapy is not beneficial (18).

In conclusion, collecting duct carcinoma, plasmocytoma and malignant fibrous histocytoma are rare but aggressive tumors of the kidneys. Surgery is the mainstay of treatment when recognized early. Accumulation of data on these tumors will allow for the establishment of better treatment strategies and prognostication.

\section{References}

1) Zambrano NR, Lubensky IA, Marino MJ et al. Histopathology and molecular genetics of renal tumors: toward unification of a classification system. J Urol;1999;162:1246-58.

2) Dimopoulos MA, Logothetis CJ, Markowitz A et al.Collecting duct carcinoma of the kidney. Br J Urol. 1993;71:388-91.

3) Fleming S, Lewi HJE. Collecting duct carcinoma of the kidney. Histopathology .1986;10: 1131-41.

4) Mostofi FK, Davis CJ, Sobin LH. Histologic typing of kidney tumours. International Histologic Classification of Tumours, No. 25. Geneva: World Health Organization, 1998.

5) Chao D, Zisman A, Pantuck AJ, et al. Collecting duct renal cell carcinoma: clinical study of a rare tumor. J Urol 2002; 167:71-74

6 ) Weichhold W, Labouyrie E, Merlio JP et al. Primary extramedullary plasmacytoma of the liver. A case report. Am J Surg Pathol. 1995 ;19(10): 1197-202.

7) Kandel LB, Harrison LH, Woodruff RD et al. Renal plasmacytoma: a case report and summary of reported cases.J Urol. $1984 ; 132(6): 1167-9$.

8) Galieni P, Cavo M, Pulsoni A et al. Clinical outcome of extramedullary plasmacytoma.Haematologica. 2000 ;85(1):4751.

9) VS38: a new monoclonal antibody for detecting plasma cell differentiation in routine sections. J Clin Pathol. 1994;47(5):418-22.

10) Strickler JG, Audeh MW, Copenhaver CM et al. Immunophenotypic differences between plasmacytoma/multiple myeloma and immunoblastic lymphoma.Cancer. 1988;61(9):1782-6.

11) Wiltshaw E: The natural history of extramedullary plasmacytoma and its relation to solitary myeloma of bone and myelomatosis. Medicine (Baltimore) 1976 ;55(3): 217-38

12) Liebross RH, Ha CS, Cox JD et al. Solitary bone plasmacytoma: outcome and prognostic factors following radiotherapy. Int J Radiat Oncol Biol Phys. 1998; 41(5):1063-7.

13) Soutar R, Lucraft H, Jackson G et al. Guidelines on the diagnosis and management of solitary plasmacytoma of bone and solitary extramedullary plasmacytoma.Clin Oncol (R Coll Radiol). $2004 ; 16(6): 405-13$.

14) Alexiou C, Kau RJ, Dietzfelbinger $\mathrm{H}$ et al. Extramedullary plasmacytoma: tumor occurrence and therapeutic concepts. Cancer. 1999;85(11):2305-14.

15) Brien J E, Stout A P. Malignant Fibrous Xanthoma. Cancer 1964.17: 1145-1155

16) Trauchen JA, Dimitrav-bona A. Malignant Fibrous Histocytoma:Expression of monocytes/macrophages differentiation antigen detected with monoclonal antibodies.Am J Pathol 1986124 303-309

17) Arny MM, Soule EH. Living JC. Malignant fibrous histocytoma:a retrospective study of 167 cases. Cancer 1980; 45: $167-178$

18) Ite C, Godween JW ,Sinkovics et al. Chemotherapy for malignant fibrous histocytoma.A South-West oncology group report.Cancer 1977:40 2010-2014 